\title{
A Study on Impact of Advertisement on Consumer Buying Behaviour with respect to O'TC Products in Katni City
}

\author{
Dr. Supriya Singh \\ Assistant Professor, Dr. C. V. Raman University, Kota, Bilaspur C. G. India
}

\begin{abstract}
The advertisement of OTC drugs plays a very important role in sale of OTC drugs in India and influence the buying decision in some aspect. The drug and magic remedies Act of 1954 and 1955 prevent advertisement of certain products that require consumption only under medical supervision. This was done in a view to prevent the self-medication for an ailment. In India the OTC drugs are allowed to be aired and are endorsed by many celebrities. Celebrities in India have a huge impact on people, so any product that is promoted by their favourite celebrity, compels them to buy that product. The impact of advertisement on sale of OTC drugs is an important subject to be studied and also to be taken into consideration that what are the most impactful ways to advertise a product. In this research we are studying the impact of advertisement of OTC products on consumer behaviour and their spending in OTC products.
\end{abstract}

Keywords: OTC products, Advertisement, Consumer, Consumer Behavior, pharmaceutical

\section{Article Publication}

Published Online: 20-Jan-2022

*Author's Correspondence

8 Dr. Supriya Singh

8 Assistant Professor, Dr. C. V. Raman University, Kota, Bilaspur C. G. India

$\underline{10.31305 / \text { rrijm.2022.v07.i01.005 }}$

$\triangle$ supriyachouhan3[at]gmail.com

(C) 2022 The Authors. Published by RESEARCH REVIEW International Journal of Multidisciplinary. This is an open access article under the CC BY-

NC-ND license

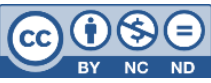

(https://creativecommons.org/licenses/ by-nc-nd/4.0/)

\section{Introduction}

The term OTC is used for over-the-counter drugs, the pharmaceutical products that are sold in the pharmaceutical or general stores without the prescription from registered medical practitioner (RMP). In India, the medicines are listed under different schedules in the Drugs and Cosmetics Act and Drugs and Cosmetics Rule. Drugs listed in Schedules H, H1, and X should carry a label stating that these drugs are to be sold by retail only on prescription of a registered medical practitioner. There are certain non-prescriptive drugs that can cause side effects to certain people and hence they should be consumed under medical supervision. The drugs of these categories are kept under schedule $\mathrm{G}$ of the rule. The schedule $\mathrm{K}$ of the rule contains list of those drugs that can be sold in the villages without any prescription from RMP that have a head count of one thousand persons or less. These drugs are commonly known as household remedies. The medicines prepared using traditional ways and non-allopathic ingredients such as herbs and plant derivatives and are of herbal origin are known as ayurvedic medicines. The medicines are natural in nature. The drugs can be sold as non-prescriptive drugs in the market.

The manufacturer of the drugs needs to take approval from the Indian drugs and cosmetic regulatory authority known as DCA and DCR before selling the manufactured ayurvedic item in the market. The sale of ayurvedic products do not require a prescription from RMP but it's the responsibility of the manufacturer to obtain a license of non-prescription medicine from the DCA and DCR and from the state licensing authorities. The DCA and DCR gives a license of non-prescription medicine only after it has tested the manufactured item for ingredients present in it. The ingredients found in the manufactured item should not have an ingredient listed in schedule $\mathrm{H}, \mathrm{X}$ or $\mathrm{G}$. 


\section{Advertisement of the Product}

Drugs are often associated with abuse. The advertisement plays a significant role in sales of products in India as it is the way to reach to masses. The advertisements of medicines and products that contain ingredients from schedule $\mathrm{H}, \mathrm{X}$ or $\mathrm{G}$ are not allowed to be aired in India. In India there exists a drug and magic remedies acts of 1954 and 1955. These acts prevent advertisement of certain products that require consumption only under medical supervision. This was done in a view to prevent the self-medication for an ailment. The drugs and magic remedies (objectionable) acts mention it clearly that advertisement of prescription only drugs are not allowed to be aired in India. This is because advertisement might invoke a tendency of self-medication on the viewers and thus leading to a subsequent drug abuse. The OPPI code of pharmaceutical marketing practices of 2010 are based on IFPMA code. The marketing representative of drug and medicine manufacturers can visit pharma stores and doctors for the advertisement of their product. However, obliging the same with gifts and lucrative deals is illegal. The nonprescriptive drugs do not hold a restriction on advertisement. The advertisement of such products can be comfortably aired in India. The advertisement should meet CCI rules and regulations strictly.

The advertisement of non-prescriptive products that are commonly aired in India are

1. Antacid's powder, tablets, liquids, gels and suspensions - Common product ENO fruit salt

2. Digestive tablets - Hajmola, SWAD

3. Rubs - vicks vapor rubs

4. Analgesic - Emami fast relief

5. Multivitamins and Micronutrients - Revital

6. Derma Care - Boroplus

7. Burn relief - Burnol

8. Anti-Dehydration - Glucon-D, Getorade

9. Lozenges - Halls

10. Cough Syrup - Torex

11. Dressing and tapes - Hansaplast

\section{Advertising of the Product and Information Search Process}

Advertisement affects subconscious decision-making ability of a consumer (Hansen \& Christense, 2007). OTC product manufacturer adopts wide range of advertising policies for promotion of their product. They employ celebrities as main protagonist. Celebrities have huge fan followings and products endorsed by them increase the probability that many fans of the celebrity will purchase it. This is because the brand and image of the celebrity gets instantly associated with the brand image of the product. The advertisement thus becomes a concealed source of information search. The information search process involves accumulation of information about the product from various sources. These sources can be in form of advertisements, opinion blogs, snippet in magazine or newspaper, one to one discussion with existing consumer, discussion with marketing representative or online discussion forums. All sources of information related to OTC product is an advertisement in direct or indirect form.

\section{Objectives}

- To determine the relationship between consumer spending pattern with respect to advertising of OTC products in Katni City.

- To see what could be the impactful ways to advertise the OTC products with reference to Katni City.

\section{Research Hypothesis-}

H0: Advertisement has no significant relationship with consumer spending.

H1: Advertisement has significant relationship with consumer spending.

H0: Advertisement has no significant relationship with demographic variables.

H2: Advertisement has a significant relationship with demographic variables. 


\section{Review of literature}

Many researchers in the past have focused on different aspects of over-the-counter medicine/drugs purchasing and consumer behaviour. Some of these noteworthy contributions have been presented below.

\section{Current State of Knowledge}

(NCPIE, 2002), in a research report stated that today out of every five Americans three American reports that they have consumer one or more OTC products in past 180 days. The report also indicated that consumption of OTC drugs in America is slightly more than consumption of prescription only drugs. The report indicated that most common OTC drugs that are consumed by Americans are for treating symptoms of heartburn, allergies, stomach problems and skin infection.

(Lodorgos, et al., 2006), the authors focused on determination of factors influencing buying behaviour related to OTC product. The primary data was collected for the study and was analysed using factor analysis technique. The factor analysis determined that factors such as trust, brand loyalty and price are the important factors affecting customer buying behaviour.

(Anderson, et al., 2008), in their research work showed the importance of the advertising in OTC product. The authors used primary data for their research work. The primary data for the research work was collected using a survey questionnaire. The variables that were collected using the survey questionnaire included continuous and dichotomous data. The data so collected was analysed using linear regression techniques. The analysis resulted in the fact that those who got influenced by the OTC product advertisement were spending more on OTC products as compared to those who were not influenced with the OTC product advertisement.

(Srivastava, 2009), the researcher performed his research work with special context to Indian OTC scenario. The author tried to determine what are the various impact of OTC product advertisements. The author with the help of questionnaire that focused on collection of consumer responses related to advertisements preformed research analysis and concluded that the consumers definitely get influenced by the advertisement at the time of buying an OTC product. However, the advertisement needs to be interesting and should not be of repetitive and sluggish genre. If the advertisement is of repetitive and sluggish genre then consumers fail to get influenced by the advertisement at the time of purchase of OTC product.

(Shaji \& Lodha, 2010), preformed their research work with special context to Indian OTC market and how Indian consumers get influenced by the product advertisement. The authors in their research work utilized primary data and collect it using a survey questionnaire. The data collected through survey questionnaire was then analysed using inferential methods. The inferential method used in their research work was a multivariate regression analysis. The analysis results indicated that the in Indian context the consumer gets highly influenced by the product advertisement. An Indian consumer will tend to spend 200 percent more on OTC products if he is influenced by the product advertisement as compared to that Indian consumer who is not influenced by the advertisement.

(Arya, et al., 2012), in their study focused on determination of buying behaviour of consumers of Jognider Nagar when it comes to purchase of OTC products. The researchers in their study adopted a non-probabilistic sampling approach for determination of sample for the study. The researchers collected primary data with the help of a survey questionnaire. The data so collected was analysed empirically. The authors concluded that $62 \%$ of the consumers showed a trend that they prefer ayurvedic composition of OTC products. The authors also deduced that the consumers were less inclined towards those OTC products that were of Unani composition.

(Chiribuca \& Hanta, 2013), in their research work focused on determination of what type of advertisement positively affects the consumer buying behaviour of people of Romania when it comes to purchase of OTC drugs. In their research work they employed a methodology that was based on the collection and empirical analysis of Review of Literature 34 primary data. The authors after performing analysis of the collected primary data determined that those OTC products have more sales which have irony, positive emotions and fantasy as a theme of their 
advertisement in comparison to those advertisements that were straight forward and targeted presentation of specific ailment and its solution through their OTC product.

(Rai, 2013), in his study tried to determine the effect of advertisement on buying behaviour related to OTC product. The authors with the help of primary data and regression analysis determined that advertisements positive affects buying behaviour related to OTC products in Indian context.

(Beevi, 2014), focused on determination of what type of advertisement positively affects the buying behaviour when it comes to purchase of OTC products. With the help of survey questionnaire, the author collected necessary primary data. Analysis the primary data the resulted that, consumers tend to get influenced by those OTC product advertisements that have emotion quotient in them as compared to those who do not have emotional quotient in them. The author suggested that repetitive advertisement strategies should be avoided by the brands and innovative marketing strategies that uses emotional quotient should be implemented in present time to promote sales of OTC products.

\section{Methodology}

- Primary Data In this research work the primary data was collected using a self-administered questionnaire. The questions belonged to psychometric analysis. The questionnaire contained one more section that focused on collection of demographic variables so that the relationship between buying behaviour related to OTC products and the demographic variables can be determined.

- Secondary Data For this research work the secondary data was collected from already existing research works that were available online, public libraries, departmental libraries and the research centre library.

- Target population - In this research work the target population was the population of consumers who buy OTC products in Katni City.

- Sample size in this research work was 800 respondents.

\section{Data Analytical Techniques}

The research analysis employs descriptive analysis and inferential analysis for deducing results from the data. The descriptive methods resulted in general trend related to consumer behaviour present in consumer of Katni city related to OTC products. The Factor analysis focus on determination of psychometric factors that affect customer buying behaviour. The methodology adopted for factor analysis in this research work was inductive modelling and exploratory factor analysis.

\section{- Descriptive analysis employs-}

1. Frequency distribution method

2. Percentage score method

3. Maximum and minimum functions

\section{- The inferential methods employed in this work consisted of}

\section{Factor Analysis}

The Factor analysis focuses on determination of psychometric factors that affect customer buying behaviour. The methodology adopted for factor analysis in this research work was inductive modeling and exploratory factor analysis.

\section{Regression Analysis}

The regression analysis was employed to study effect of demographic variables on the consumer buying behaviour. The expenses on OTC products per month by the consumers were considered as direct indicator of consumer buying behavior (Ampofo, 2014).

The buying behaviour was considered as dependent variable while the influence of advertisement is considered as independent variables. Hypothesis framed for this research work was also tested using the regression methods. 
Deterministic analysis of the number of respondents influenced by advertisements

Table-1

\begin{tabular}{|l|l|l|}
\hline \multicolumn{1}{|c|}{ Status } & Number of Respondents & Percentage Population (\%) \\
\hline Not Influenced & 55 & 6.87 \\
\hline Influenced & 745 & 93.13 \\
\hline Total & $\mathbf{8 0 0}$ & $\mathbf{1 0 0}$ \\
\hline
\end{tabular}

From the table, it is evident that 55 respondents were not influenced by the advertisement while 745 respondents were influenced by the advertisements. Percentage wise 6.87 percent of the population was not influenced by the advertisement while 93.13 percent of the population was influenced by the advertisement of the OTC product.

Response on influence of tv commercials when it comes to buying of OTC products

Table- 2

\begin{tabular}{|l|l|l|l|}
\hline S. No. & \multicolumn{1}{|c|}{ Responses } & No. of Respondents & Percentage Population $\%$ \\
\hline 1 & Strongly Disagree & 39 & 4.88 \\
\hline 2 & Disagree & 91 & 11.38 \\
\hline 3 & Neutral & 218 & 27.25 \\
\hline 4 & Agree & 326 & 40.75 \\
\hline 5 & Strongly Agree & 126 & 15.75 \\
\hline $\mathbf{6}$ & Total & $\mathbf{8 0 0}$ & $\mathbf{1 0 0}$ \\
\hline
\end{tabular}

From the above table it is evident that 39 people strongly disagree with the influence of TV commercials when it comes to purchase of OTC products. 91 respondents disagree, 218 respondents were neutral about the question, 326 respondents agreed and 126 respondents strongly agree that they were influence by the TV commercial.

Response on influence of favourite superstar endorses the product

Table- 3

\begin{tabular}{|c|l|l|l|}
\hline S. No. & Responses & No. of Respondents & Percentage Population $\%$ \\
\hline 1 & Strongly Disagree & 48 & 6 \\
\hline 2 & Disagree & 94 & 11.75 \\
\hline 3 & Neutral & 218 & 27.25 \\
\hline 4 & Agree & 255 & 31.88 \\
\hline 5 & Strongly Agree & 185 & 23.13 \\
\hline $\mathbf{6}$ & Total & $\mathbf{8 0 0}$ & $\mathbf{1 0 0}$ \\
\hline
\end{tabular}

When asked about the influence of their favourite superstar endorsing the product the response was: 48 were strongly disagree, 94 were disagree, 218 respondents were neutral, 255 respondents were agreeing and 185 respondents out of 800 were strongly agree.

Response on the influence of the commercial addressed the ailment exactly in the same way the respondent is suffering.

Table- 4

\begin{tabular}{|c|l|l|l|}
\hline S. No. & \multicolumn{1}{|c|}{ Responses } & No. of Respondents & Percentage Population $\%$ \\
\hline 1 & Strongly Disagree & 37 & 4.63 \\
\hline 2 & Disagree & 48 & 6 \\
\hline 3 & Neutral & 193 & 24.13 \\
\hline 4 & Agree & 287 & 35.88 \\
\hline 5 & Strongly Agree & 235 & 29.38 \\
\hline $\mathbf{6}$ & Total & $\mathbf{8 0 0}$ & $\mathbf{1 0 0}$ \\
\hline
\end{tabular}


From the above table it is evident that, 37 respondents strongly disagreed, 48 were disagree, 193 were neutral, 287 were agree and 235 respondents strongly agreed that they get influence by the commercial that addresses the ailment exactly in the same way the respondent is suffering.

Model obtained from regression analysis

\begin{tabular}{|l|l|l|l|l|l|}
\hline Coefficient & Unstandardized Coefficients & Standardized co-efficients & t & Sig. \\
\hline Model & B & Standard error & Beta & & \\
\hline & 111.484 & 13.85 & & 8.049 & 0 \\
\hline (Constant) & 10.136 & 0.13 & 6.228 & 0 \\
\hline $\begin{array}{l}\text { Advertiseme } \\
\text { nt Influence }\end{array}$ & 63.124 & 13 & & \\
\hline a Dependent Variable- Expenses
\end{tabular}

The above table of regression analysis shows that independent variable advertisement is significant at $5 \%$ significant level so it is concluded that variable advertisement has a significant relationship with the consumer spending on OTC product

\section{Conclusion from descriptive analysis-}

1. TV commercial are so penetrating and convincing that they affect customers mindset related to purchase of OTC products. Hence, customers stated that they get influenced by advertisement when they go for purchase of OTC products.

2. People have their favourite superstars. People patronize them. Hence, any product endorsed by them would be compelling for a fan to buy it.

3. OTC product advertisement focus on depiction of ailment with help of a protagonist. These advertisements are so structured that they strike Research Conclusion and Summary 172 customers mentality and instantly connects with the customer mindset and induces a thought that they are also suffering from the same ailment. This depiction affects customer buying behaviour related to OTC products and the same was exhibited by the customers of Katni district.

Conclusions from Inferential Analysis-

\begin{tabular}{|c|c|c|c|}
\hline Variable & $\begin{array}{c}\text { Relationship with Consumer } \\
\text { buying behaviour when it comes } \\
\text { to purchase of OTC products }\end{array}$ & Level & $\begin{array}{c}\text { Effect of buying } \\
\text { behaviour }\end{array}$ \\
\hline $\begin{array}{c}\text { Advertisement } \\
\text { Influence }\end{array}$ & Significant at 5\% significance level & $\begin{array}{c}\text { Influenced by } \\
\text { advertisement } \\
\text { of product }\end{array}$ & $\begin{array}{c}\text { Spending on OTC } \\
\text { product increases by } \\
\text { 63.35 Rupees }\end{array}$ \\
\hline
\end{tabular}

From the above tables it is evident that Advertisement has a significant relationship with buying behaviour, the influenced customer spends more on OTC product.

\section{Suggestions}

Digital marketing strategies should be adopted. Pamphlets distribution now a day is seldom effective. Pushing advertisement through mobile applications that have huge customer base should be adopted.

If a new OTC product is being launched, then the manufacturers can adopt vivid marketplace practices such as being online only approach. This increases exclusive quotient of the product and induces curiosity in the prospective customers. It is being suggested that if the manufacturers adopt such marketplace model than they wisely choose the e-commerce platform, as products image will also depend on online retailer's image. 


\section{Acknowledgement}

I would like to thank Dr. Manoj Kumar Khare for his valuable support and guidance. I also thank the survey participants for their valuable contribution for this research work, I thank my family members for their constant support during my research.

\section{References}

Aker, J., Beck, M., Travis, S. \& Harris, J., 2014. Consumer navigation and selection behaviors for OTC products in a retail setting, Indianapolis: Concentrics Research.

Ampofo, A., 2014. Effects of advertising on consumer behaviour: with reference to demand for cosmetic products in Banglore, India. New media and mass communication.

Anderson, S. P., Ciliberto, F. \& Liaukonyte, J., 2008. Getting into your head(ache): Advertising content for OTC analgesics, Virginia: Marketing science institute.

Arya, V., Thajur, R., Kumar, S. \& Kumar, S., 2012. Consumer buying behaviour towards ayurvedic medicines/products in Joginder Nagar - A survey. IJAAS, 1(3).

Beevi, F. A., 2014. Power of advertisement on buying habits of women. Abhinav international monthly refereed journal of research in management and technology, 3(7).

Chiribuca, D. \& Hanta, A., 2013. Drug advertising - configuration factos and communication strategies: A case study on television broadcasted advertisements in Romania. Revista de cercetare si interventie sociala, 41(1).

Hansen, F. \& Christense, S., 2007. Emotions, advertising and consumer choice. 1st ed. Sentrum: Copenhagen business school press.

Keith, M. \& Jesus, S., 2017. SPSS statistics for Data Analysis and Visualization. Delhi: Wiley. Hamelin, A.-M. et al., (1999).

Lodorgos, G. N., Mulvana, K. L. \& Temperley, J., 2006. Consumer behaviour: experience, price, trust and subjective norms in the OTC pharmaceutical market. Special edition on consumer satisfaction - Global perspective, 1(1).

NCPIE, 2002. Attitude and beliefs about the use of over-the-counter medicines: A dose of reality, New-Delhi: HarrisInteractive.

Rai, N., 2013. Impact of advertising on consumer behaviour and attitude with reference to consumer burables. International journal of managment research and businness strategy, 2(2).

Shaji, J. \& Lodha, S., 2010. Regulatory status of banned drugs in India. Indian J.pharm.educ.res, 44(1).

Srivastava, R. K., 2009. Attitudes of consumers towards the pharma OTC products in India. Business studies journal, 1(2).

Spiegel, M. \& Stephens, L. J., 2006. Theory and problems of statistics. New York: McGraw Hills.

Stephens, L. J., 2006. Beginning Statistics. New York: McGraw Hill. Tjora, A., 2018.

Qualitative Research as a Stepwise- Deductive Induction. 1st ed. London: Routledge.

World Self Medication Industry, 2008. Advertising of nonprescription medicines to the public, Chicago: SWMI. 